\title{
Narrative Technologies: A Philosophical Investigation of the Narrative Capacities of Technologies by Using Ricoeur's Narrative Theory
}

\author{
Mark Coeckelbergh ${ }^{1} \cdot$ Wessel Reijers $^{2}$
}

Published online: 2 March 2016

(c) The Author(s) 2016. This article is published with open access at Springerlink.com

\begin{abstract}
Contemporary philosophy of technology, in particular mediation theory, has largely neglected language and has paid little attention to the social-linguistic environment in which technologies are used. In order to reintroduce and strengthen these two missing aspects we turn towards Ricoeur's narrative theory. We argue that technologies have a narrative capacity: not only do humans make sense of technologies by means of narratives but technologies themselves co-constitute narratives and our understanding of these narratives by configuring characters and events in a meaningful temporal whole. We propose a hermeneutic framework that enables us to categorise and interpret technologies according to two hermeneutic distinctions. Firstly, we consider the extent to which technologies close in on the paradigm of the written text by assessing their capacity to actively configure characters and events into a meaningful whole; thereby introducing a linguistic aspect in the theory of technological mediation. Secondly, we consider the extent to which technologies have the capacity to abstract from the public narrative time of actual characters and events by constructing quasi-characters and quasi-events, thereby introducing the social in our conception of technological mediation. This leads us to the outlines of a theory of narrative technologies that revolves around four hermeneutic categories. In order to show the merits of this theory, we discuss the categories by analysing paradigmatic examples of narrative technologies: the bridge, the hydroelectric power plant, video games, and electronic money.
\end{abstract}

Mark Coeckelbergh

mark.coeckelbegh@univie.ac.at

Wessel Reijers

wreijers@computing.dcu.ie

1 Department of Philosophy, University of Vienna, Universitätsstraße 7, 1010 Vienna, Austria

2 ADAPT Centre, School of Computing, Dublin City University, Henry Grattan Building, Dublin 9, Ireland 
Keywords Narrative technologies $\cdot$ Mediation $\cdot$ Narrative theory $\cdot$ Ricoeur $\cdot$ The social $\cdot$ Language

\section{Introduction}

In recent critiques of contemporary strains of works in philosophy of technology that focus on mediation, two main concerns appear to be prevalent: neglect of language and neglect of the social in human dealings with technology. Since the "empirical turn" (Achterhuis 2001) in the philosophy of technology, the hermeneutic theories of technology that offer a critique of language and technology (Heidegger, Ellul) were largely dismissed, which was accompanied by the credo "to the things themselves" (Verbeek 2005: 12) — thereby sacrificing the analysis of language for the analysis of the material dimension of technology (Coeckelbergh 2015a). Moreover, although it heavily borrowed from STS, philosophy of technology (especially mediation theory) began to focus on the individual level, on "how subjects and objects are co-shaped rather than how societies and objects are co-shaped" (Kaplan 2009: 236). For this reason, it failed to account for ways in which "being-with-each-other" relations are instantiated, of how intersubjective relations are mediated by technologies (Van Den Eede 2010: 140). We aim at overcoming the neglect of language and of the social in such inquiries about technology.

The urgency of this endeavour is highlighted by discussions outside of philosophy on the ways technology and language interact in order to shape intersubjective relations. In legal studies, Lawrence Lessig argues that the architecture of computer code regulates our social relations in a similar way law does (Lessig 2006: 235). In economics, the implications of coding language on the economic concept of the digital commons is emphasized by (Hess and Ostrom 2003). In computer science, Bergstra and Leeuw (2013) consider the ways in which the design of computer protocols (language) can impact both the legal concept of ownership (law) and the economic concept of money. What can be derived from such academic deliberations is that language, technology, and the social interrelate and coconstitute one-another. By providing a holistic account of how these apparently separate spheres mediate one-another, philosophy of technology can add to the debate.

In order to restore attention to the technological mediation of language and of inter-subjectivity, we may look within philosophy of technology (for example the earlier work of Ihde on technology and hermeneutics) or we may look elsewhere (e.g., philosophy of language, phenomenology, and hermeneutics not usually associated with philosophy of technology) and explore implications for philosophy of technology, in particular for mediation theory. In this paper we choose the latter route: we use the work of Ricoeur to propose a framework to discuss what we call "narrative technologies". Though Ricoeur has already been brought to the attention of philosophers of technology (Kaplan 2006), a thorough discussion of the way in which his narrative theory can assist or understanding is still absent.

The impact of narrativity on the design of technology and the constitution of social life becomes apparent by reviewing literature in different disciplines. In the 
field of computer science, game designers argue that "choices about the design and organisation of game spaces have narratological consequences" (Jenkins 2003: 129) and researchers in artificial intelligence argue that the richness of "narrative intelligence" might solve enigmas resulting from the simplicity of formal understandings of computer intelligence (Mateas and Sengers 1999). The social significance of narrativity becomes apparent in discussions about narrative in law and history of technology. It is argued that narrative constitutes an important aspect of legal judgement that goes against pure formalist conceptions of law (Patterson 1990). Moreover, social scientists show that technologies like the Internet are embedded in a "cultural-narrative" (Goodfellow and Hewling 2005) and that historical events like the Fukushima nuclear disaster are understood according to multiple narratives that show an interplay of technology, politics, and society (Jones et al. 2013). Hence, narrativity is an issue of great interest for studies of technology, the humanities, and for the social sciences.

The question that guides the inquiry in this paper is whether Ricoeur's narrative theory discloses an understanding of technology that includes an account of how technology mediates language and inter-subjectivity. We start by elaborating on the neglect of language and the social in philosophy of technology and on the way Ricoeur incorporates them in his theories. Subsequently, we present a brief exposition of the concept of configuration in Ricoeur's narrative theory, followed by a discussion of the implications of his theory for our understanding of technology. Accordingly, we construct a theory of narrative technologies based on Ricoeur's narrative theory that clarifies the narrative capacities of technology according to the distinctions between passive and active and between abstract and engaging narrative technologies. We discuss the analytic merits of these hermeneutic distinctions by examining the technological mediations of four paradigmatic technologies (the bridge, the hydroelectric plant, video games, and monetary technologies) in light of our narrative framework.

\section{Language and the Social in Ricoeur's Narrative Theory}

Contemporary philosophy of technology, in particular mediation theory, discusses how technologies shape subjectivity and how they mediate agency-perhaps even possess agency as non-human actors. For example, Verbeek shows that experiences and actions are materially, technologically mediated (2005: 123). New technologies change, or rather co-shape our mediated subjectivity. Yet, in these theories and discussions considerations with regards to the role of language are often simply absent. There is a subject and an object, there are persons and artefacts, there are human and non-human agents, but words, sentences, grammar, and narratives do not enter the stage. This is not only problematic because of the impoverished conceptualisation of subjectivity and self as having little to do with language; it also neglects the social-linguistic environment and horizon, which is entangled with technologies and technological practices.

This neglect illustrates how mediation theory became divorced from its main intellectual sources: it is inspired by Ihde's (post-) phenomenology, but in its urge to reject what it takes to be Heideggerian "pessimism" it turned to the artefact, to 
"things" (Verbeek 2005). By doing so, it has become remote from a central theme in phenomenology and hermeneutics: language. Moreover, it has heavily borrowed from Science and Technology Studies (STS), but has used its concepts mainly to highlight the material-personal aspects of technologies while neglecting their linguistic-social dimensions. For example, mediation theory has used work by Latour and Akrich to talk about the "script" of artefacts, but this concept has been mainly used metaphorically to focus on the agency of artefacts without paying attention to the suggestion that there may be a sense in which artefacts write or speak, a way in which technologies have a linguistic dimension. Furthermore, the script of artefacts as borrowed from actor network theory is treated as if it is isolated from a wider social-linguistic environment (prescriptions, discourse, narratives).

We propose to remedy the neglect of language and the social in contemporary philosophy of technology (and in particular postphenomenological mediation theory) by introducing the concept of "narrative technologies". To put this concept to work we require a theory of narrative, for which we will draw on the work of Paul Ricoeur, who is widely known for his insights into the narrative and social aspects of the human being but whose work has been rarely used in philosophy of technology. An exception to this silence is a paper by David Kaplan, which identifies ways in which Ricoeur can contribute to philosophy of technology. First of all, Kaplan argues that text discussed by Ricoeur as "a paradigm for the linguistic mediation of experience" (2006: 49), is similar to technologies that are "readable". Moreover, he argues that Ricoeur's work can explicate the ways in which technologies mediate social meanings. Finally, he asserts that Ricoeur can assist philosophy of technology in explicating the "different ways that technologies figure into our lives" (2006: 50). However, Kaplan remains silent about what a proposed synthesis of philosophy of technology and Ricoeur's work might actually look like: about how we can understand technologies by deploying this theoretical framework. We aim at going beyond the mere identification of theoretical advantages by integrating them into an actual theory of narrative technologies.

Before going into Ricoeur's theory of narrativity, we briefly reflect on the position of narrative in philosophical debates. Two major points of divergence can be distinguished. Firstly, an opposition exists between those who consider narrative as an instrumental cognitive ability - a cognitive ability to impose meaningful order onto human reality or experience-and those who consider it as an ontological category that is indivisible from the way humans are in the world (Meretoja 2014: 89). One the one hand, scholars such as White and Mink characterise narrative as a "manner of speaking" (White 1980: 7) or a "mode of comprehension" (Mink 1970: 549) of aspects of the world. On the other hand, others such as MacIntyre and Ricoeur argue for the "narrative character of human life" (MacIntyre 2007: 144) and point to the relation between narrative and time: "time becomes human to the extent that it is articulated through a narrative mode" (Ricoeur 1983: 52; original emphasis). Secondly, an opposition exists between those who defend an empiricist tradition that assigns primacy to the human immediate experience of the present and therefore denounces narrative as a fundamental philosophical concept and those who reject the idea of unmediated experience in support of the philosophical significance of narrative. Philosophers such as Strawson and Sartre claim that 
human experience is not necessarily mediated by narrative (Strawson 2004: 429) and that "unmediated awareness is basic" (Duncan 2005: 108), by which they oppose thinkers such as Taylor, who argues for a "science of interpretation" (Taylor 1971: 4) based on the presupposition that all representations of the world are mediated by human interpretation. Ricoeur belongs to the philosophical tradition that supports narrative as an ontological category and therefore as a fundamental mediator of human experience. As such, he rejects the Cartesian notion of direct access to oneself and "reflects on how subjectivity is always mediated by the "long detour' of 'signs, symbols and texts"” (Meretoja 2014: 96). In order to show how Ricoeur incorporates the two enigmas of contemporary philosophy of technology discussed previously, we will consider the role of language and the social in his work.

\section{Ricoeur and Language}

Unlike philosophers who focus on the material dimension of technological mediation, Ricoeur has a primary interest in human language. In his writings about language, he incorporates ideas from both the Anglo-American tradition (commonly referred to as "analytic") and the European tradition (commonly referred to as "continental"); which motivate him to go as far as comparing the works of two philosophers who are at face value each-others opposites: Husserl and Wittgenstein (Ricoeur 2014). In his interpretation of works of language, he especially focuses on the "grasp of language on experience" (2014: 29), on the way human language mediates human experience. To illustrate this grasp of language on experience, we can consider our knowledge of traffic rules (when such-and-such a situation occurs, I react like this) as a determinant of our experience of a traffic situation, or our knowledge of ritualistic protocols during the experience of a ceremony (e.g., the installation of a new president occurs when such-and-such declarations are uttered). In both these cases, the way we experience the situation is mediated by our understanding and use of language. Central to Ricoeur's understanding of language lies the interpretation of text, which he argues can be seen as a model for meaningful action. Put differently, Ricoeur argues that humans interpret their everyday actions as configured by narratives, of which texts are the paradigmatic reification (Meretoja 2014: 98). A very clear example of such a text is a diary, in which personal interpretations of every-day action are recounted (Hassam 1990).

Ricoeur's ideas about language are strongly influenced by Heidegger, though he is much more sympathetic to formalist theories that aim at providing atomistic explanations of language. A major premise that Ricoeur employs throughout his work is that human linguistic-mediated experience is characterised by temporality: by the "within-time-ness" of human experience. Human experience and action, according to Ricoeur, are essentially mediated by language within a temporal setting, and hence are not dependent on point-like, unmediated experiences of the present. In "Narrative Time," Ricoeur asserts: "my first working hypothesis is that narrativity and temporality are closely related-as closely as, in Wittgenstein's terms, a language game and a form of life" (1980: 169). As such, when we consider the "time" of an action ("it's time to go to work"), our temporal understanding of 
the world is mediated by language in the narrative form. Just how closely narrativity and temporality are related is the major subject of discussion in Ricoeur's seminal work Time and Narrative, which will be our major source for constructing a theory of narrative technologies.

At this point we have shown what Ricoeur has to offer to our understanding of language and narrative, which will enable us, in a later section, to address the neglect of language in contemporary philosophy of technology. But we still need to say more about the social in order to address the neglect of the social. What role does the social play in Ricoeur's work?

\section{Ricoeur and the Social}

Throughout his work, Ricoeur stresses the importance of interpreting human existence by considering its embeddedness in human social reality. In line with the "within-time-ness" of the individual, Ricoeur argues: "the time of narrative is public time" (1980: 175; emphasis added). Moreover, he asserts "public time, as we saw, is not anonymous time of ordinary representation but the time of interaction. In this sense, narrative time is, from the outset, time of being-with-others" (1980: 188). Hence, Ricoeur asserts that the social is explicitly present in narrative time, which remains a time of interactions between people without being made anonymous, separated from human experience and action (as for example can conversely be said about the time of science that is derived from natural laws rather than from human experience).

Because narrative time is a public time that is not detached from the human spheres of experience and action, Ricoeur perceives the reification of narrative in written text as the paradigmatic object of hermeneutics (1971: 316). In successive order, Ricoeur asserts that the time of human experience and action is made public in narrative time and that narrative time finds its reification in written text. Hence, through the retrodiction of text, which entails the utilisation of textual information to infer or explain an event or state of affairs, Ricoeur asserts that one can analyse the public time of human action and experience. ${ }^{1}$ In other words, we can gain knowledge about the social by means of retrodiction of narrative aspects of texts.

In order to address the role of the social in Ricoeur's work and the way it matches with our focus on technology, it seems worthwhile to draw a line of comparison between the critique of technological mediation of Van Den Eede and Ricoeur's narrative theory. When we consider Van Den Eede's critique of technological mediation we can observe that he uses a term that is almost similar to Ricoeur's "being-with-others": the technological mediation of "being-with-each-other" (2010: 140). Van Den Eede argues that these intersubjective mediations, which he claims are largely neglected by theories of technological mediation, are specifically applicable to ICTs because they are highly mediated by linguistic constructs. However, we will propose a broader application of Ricoeur's theory and

\footnotetext{
1 Notably, such use of the characteristics of narrative in order to understand narrative as a "form of natural action description” is also taken up by structuralist approaches (van Dijk 1974: 287).
} 
turn to his work in order to solve the gaps of language and the social in theories of technological mediation in general.

\section{Ricoeur's Narrative Theory}

Before we turn towards the question of narrative technology we now engage in a brief and systematic compendium of Ricoeur's narrative theory, focusing on his account of configuration as this concept will be central in our further enquiry. The starting point for the formulation of Ricoeur's theory is the hypothesis that "time becomes human to the extent that it is articulated through a narrative mode, and narrative attains its full meaning when it becomes a condition of temporal existence" (1983: 52; emphasis in original). We might need to recall that Ricoeur considers temporal existence particular to humans as a social existence, while he considers narrative time to be a public time. Put differently, human temporal experience embedded in a social setting is shaped through a narrative mode of language.

What then, is this "narrative mode"? Ricoeur claims that the mediation between time and narrative that is implied in this mode revolves around a process that he designates as emplotment. He derives his theory of emplotment from Aristotle's Poetics, grounding it in three stages of mimesis, meaning "the active process of imitating or representing something" (1983: 33). Aristotle himself says about mimesis that "the instinct of imitation is implanted in man from childhood" and that man has the "instinct for 'harmony' and rhythm" (1902: 15). Thus, the significance of understanding this process goes beyond the realm of literature and finds its philosophical substance in its purported grounding in human existence in general. Aristotle's definition of mimesis is derived from the overriding principle of muthos, which designates the plot. "The plot is the imitation of the action:- for by the plot I mean here the arrangement of incidents" (Aristotle 1902: 25). From this, Ricoeur derives that emplotment designates the organisation of events (incidents ${ }^{2}$ ) by which people represent action in a plot. Paradigmatic examples are works of tragedy and comedy in which characters imitate probable accounts of human actions structured according to a play script, which is an organisation of events (or "acts").

In a narrative like a tragedy, the plot configures different elements like characters, motivations, and events in a meaningful whole. Emplotment, so to say, creates a harmonious concordance out of discordant, heterogeneous elements. Therefore, the movement of a plot is a teleological principle, an "inexorable movement that drives the story toward an anticipated conclusion" (Dowling 2011: 6). It makes us say: this story makes sense. How then, does emplotment shape the human experience of public time? Essentially, this amounts to the movement of prefigured time that becomes a refigured time through the mediation of configured time (Ricoeur 1983: 54). For instance, when reading Plato's allegory of the cave our prefigured ideas of human knowledge in the prefigured time (before reading) change by means of the text in the configured time (during reading) and is subsequently synthesised with our experience

\footnotetext{
${ }^{2}$ Ricoeur explicitly refers to "events" rather than "incidents" while he later in his work concludes that an event as implied in a text might cover a very extensive time-span (1983: 217).
} 
of the world in the refigured time (after reading). The reading of Plato's allegory, so to say, changes our experience of the world. This movement of "narrative time" is formed by means of emplotment, and consists of three moments:

- Mimesis $_{1}$ : the pre-figurative phase. This phase consists of the understanding of the world of action: its semantics, its symbolic order, and its temporality.

- Mimesis $_{2}$ : the configurative phase, constituted by emplotment. Emplotment is the organisation of events, both chronologically (according to an episodic sequence) and a-chronologically (reflecting between the parts and the whole with a sense of ending).

- Mimesis $_{3}$ : the refigurative phase of reading. This concludes the narrative circle, of applying narrative to the world of action.

Mimesis $_{1}$ refers to our pre-understanding of the human world of action. According to Ricoeur, this pre-understanding can be analysed by considering its three basic conditions: human competence to identify action in terms of its structure, human competence to identify the symbolic mediations of actions, and the human understanding of the temporal elements of action. As such, mimesis ${ }_{1}$ indicates the initial moment at the beginning of the reading of a text, a moment that is embedded in a social context-in a human 'repertoire' from which we engage with new social phenomena. However, mimesis ${ }_{1}$ extends beyond the text, while it concerns the realm of human action in a social setting that is already mediated by narrative. For example, we understand the act of going through the passport control at an airport because we understand the structure of the act (if I'm asked my passport, I hand it over), we understand the symbolic mediations ("EU" desk for EU citizens) and we understand the temporal setting (first I do $\mathrm{x}$, then the official does $\mathrm{y}$ ).

Mimesis $_{2}$, the stage of narrative configuration, is central in Ricoeur's work and makes explicit how a narrative can configure our pre-figured time. Since it constitutes the principal feature of our theory of narrative technologies, we put our central focus on it. The key notion of narrative configuration is the movement of emplotment: the mediation of pre-figured time my means of a plot. The plot mediates between individual events and the whole of a story, it brings together heterogeneous factors (agents, goals, interactions) belonging to the realm of action (mimesis 1 ) into a syntagmatic order and it mediates the temporal dimensions of prefigured time. For instance, in the famous narrative Oedipus Rex several heterogeneous characters (Oedipus' mother, his lover, his father, the king), events (prophecies, trials, and murders), and goals (trying to evade the prophecy, aiming to know its truth) are brought together in a syntagmatic narrative whole, which constitutes the story's surprising, but acceptable, resolution. Ricoeur elaborates upon the mediation of pre-figured time by introducing the idea of two temporal dimensions in the process of emplotment: chronological and a-chronological dimensions of narrative time. The chronological dimension is concerned with an episodic arrangement of events, which characterises the narrative in terms of sequence of events (firstly this happened, secondly this happened) (Ricoeur 1983: 66). The a-chronological dimension of narrative time is concerned with the configuration of events in a meaningful whole. This implies that the organisation of 
events is made intelligible, or rather "followable" (referring to the human ability to "follow" a story) in such a way that the order of events leads to a conclusion that characterises the narrative as a whole; that renders its resolution, according to Ricoeur, acceptable for the reader. It is through the mediation of the a-chronological temporal dimension of a narrative that we can proclaim: this story makes sense.

In order to clarify the opposition between the chronological and a-chronological (configurational) arrangements, Ricoeur mentions three ways in which they differ, by mentioning capacities of a-chronological configuration that are absent in purely chronological arrangements: (1) the capacity to oscillate between events and the meaning of the story as a whole, (2) the capacity to impose a sense of ending on a narrative, and (3) the ability to "read time" backwards, from ending to beginning and beginning to end. Although a purely chronological account of an event would imply a sequence from minute to minute or from year to year (like keeping a formal $\log$ ), a narrative can relate events to a whole ("D-day was the turning point of the Second World War"), it can include a sense of ending ("the funeral of Hektor indicated the end of the Troyan war") and it can be read backwards or forwards (including "flashbacks" like in Virgil's Aeneid).

Subsequently, we highlight two aspects of the configurative phase of emplotment that are of importance for our theory of narrative technologies. Firstly, Ricoeur argues that the conclusion of a narrative does not need to be predictable but rather acceptable. To defend this claim, he analyses the notion of causal explanation in the paradigm of historical narratives (being narratives about "real" events as opposed to fictional narratives). Although he rejects the idea of historical explanation with recourse to laws, he tries to preserve causal analysis and rational explanation in history (1983: 128). If we consider explanation of historical facts, Ricoeur argues, we ask for a necessary condition and not for a sufficient, law-like condition. For example, if we ask: "how was it possible that Austria-Hungary declared war on Serbia in 1914?" we might ask for a necessary condition, which was the assassination of Franz Ferdinand. However, the murder is not a sufficient condition for the declaration of the war. In order to explain historical facts, we need to take into account the teleology that guides the events that make up history, which is grounded in the world of action of individual people. History is concerned with the realm of action, but action that is placed in a society that has already been configured through narrative activity. For these reasons, we can only explain a historical fact by means of retrodiction, not by prediction. This claim is important for our understanding of technological mediation, for it enables us to argue against technological determinism. If technologies mediate human narrative time, as we argue, they only provide for necessary reasons and not for sufficient reasons for technologically mediated action. Things could have turned out differently.

Secondly, Ricoeur discusses the way in which structures in historical narrative can be abstracted from the configured time of the plot. For example, when we make assertions like "Germany attacked France in May 1940": we do not refer to actual events with actual characters but to abstracted instances of those. However, Ricoeur argues that as soon as we try to subject such a historical statement to causal explanation, we eventually enter the configured time of mimesis ${ }_{2}$. In this mode of explanation, we would need to include the agency of people that act in a historical 
context. For instance, if we would ask for an explanation of the historical statement discussed above, a historian could start by saying something like "Hitler ordered the creation of a new military policy in case the Western powers would reject his peace proposal after his invasion of Poland...". Hence, the historian would focus his attention on actual events (an order) and characters (the leader, his generals) in a plot, thereby moving from second and third order to first order entities. For that reason, Ricoeur argues that second and third order entities in history can be considered as "quasi-events" and "quasi-characters" that figure in "quasi-plots". They are abstractions of actual characters and events but nonetheless refer back to those in the case explanations are asked for. This is important to note for our understanding of technologies because it provides for an understanding of the ways in which technologically mediated characters and events can be abstracted from actual human characters and events. The following scheme provides an approximate representation of the way second and third order entities in history refer back to the narrative level and therefore the realm of human action according to Ricoeur's theory.

\section{Levels of Configuration in Historical Narrative}

I Action (Mimesis ${ }_{1}$ ): the level of action of people in society that is already prefigured through narrative activity.

II Emplotment (Mimesis 2 ): the level of organisation of events in which characters operate.

III First order historical entities: the level of characters in historical narrative that refer back to level I, through level II.

IV Second and third order entities: the level of historical entities like countries and civilizations that refer back to level III through a dissonance between explanatory structures. These entities constitute "quasi-events," "quasi-characters," and "quasi-plots".

At this point, we can summarise the core theory of mimesis $_{2}$, the configuration phase in narrative activity. A text configures our narrative understanding my means of the plot, which refers to the organisation of events. This organisation includes a chronological sequence of events and an a-chronological organisation of these events to constitute a narrative. A plot can be explained by assessing the probability of its conclusion, which can be done by means of retrodiction: considering necessary but not sufficient conditions. Actual characters and events in the plot can be abstracted into quasi-characters and quasi-events in a quasi-plot. We can trace back these quasi-elements of a story by considering their analogical use in relation to the actual characters figuring in actual events.

To finish, we will only shortly touch upon mimesis ${ }_{3}$, while it is predominantly mimesis $_{2}$, the configuration phase that will inspire the construction of our theory of narrative technologies. The refiguration of narrative, or the application of the narrative, designates the "intersection of the world of text and the world of the hearer or reader" (Ricoeur 1983: 71). Hence, this phase of the narrative "closes" the narrative circle: we have finished reading a text whereby our narrative understanding has been transformed. We see the world in a different light, so to say, because our prefigured time has been refigured through the configuration of the text. 


\section{Towards a Theory of Narrative Technologies}

This paper is meant as an initial step in the development of a comprehensive theory of narrative technologies. In the previous section we showed how Ricoeur deals with the aspects of language and the social in his work. In line with this analysis, we argue that his narrative theory would be suitable for dealing with these aspects that have been so far largely neglected in philosophy of technology. Moreover, we drafted the outlines of Ricoeur's narrative theory in order to have the basis of our theoretical apparatus in place. In the following section, we will construct the outlines of a hermeneutic theory of narrative technologies that opens up a novel way of thinking about technological mediation.

\section{Narrative Beyond Storytelling: From Text to Technology}

As an initial concern, we face the challenge of reconciling Ricoeur's narrative theory with an understanding of technology. At face value, textual narratives and material technologies seem to be far apart. Consider for instance the apparent gap between literary texts that Ricoeur (1985) deals with in the second volume of Time and Narrative like Proust's Remembrance of things past and technologies like cars, computers, and cameras. Stories are completely made up of words and sentences while cars are made up of materials like plastics and steel. However, Ricoeur (1985) already points at the generality of his theory by mentioning a taxonomy of classes of narrative that includes "myths, folklore, fables, novels, epics, tragedies, dramas, films, comic strips, to say nothing of history, painting and conversation". Moreover, he claims that the narrative understanding engraved in history also applies to disciplines like "cosmology, geology, and biology" (1983: 135). Thus, his theory of narrative configuration can go beyond the works of literary fiction and history and can even include visual objects like paintings and knowledge in the scientific field of biology.

One of the reasons why Ricoeur himself remains relatively silent on the topic of technology is because he seemingly upholds a dichotomy between technological rationality and knowledge about the human world as it is expressed through history and fiction ${ }^{3}$ (Kaplan 2002: 2). Ricoeur's inquiry seems to be exclusively limited to knowledge about the human world of culture. In Questioning Technology, Feenberg discusses a similar dichotomy, by problematizing Habermas's distinction between "an objective realm of technically rational means and a subjective realm of ends values and means" (1999: 177). Both Habermas and Ricoeur, so it seems, aim at preserving a realm of objective rationality in our design and use of technology that is freed from human acts of subjective valuation. However, such a standpoint is untenable when considering the necessity of including the "use-context" (Ihde

\footnotetext{
${ }^{3}$ However, Ricoeur's stance on technology might actually be more nuanced, while he places himself between Habermas and Gadamer on the issue of tradition and the role of language (Bilimoria 1998). He argues that all of language is built on tradition (pre-figured reality), but that it can still function as an innovative means for formulating a critique on tradition (re-figured reality). If we place technology in this discussion, the dichotomy proposed earlier seems to be fairly weak while Ricoeur actually endorses the view that all understanding (also technical understanding) is embedded in a tradition.
} 
2009; Verbeek 2005) or the "realisation" (Feenberg 1999) of technologies while investigating their meaning. Technologies cannot be understood as isolated entities, but only through a consideration of their use in human interaction.

Once we dismiss the strict dichotomy between technical understanding and narrative understanding, we open up the possibility of employing the latter to investigate the first. To do so, we need to ask: to what extent can it be said that technology brings about a "plot" in similar ways as a text does? In other words, the central question for thinking about technologies in a "narrative" way is: can technologies configure our narrative understanding in similar ways as written texts do? Kaplan has already given some initial answers to this question. He argues that narrative theory can be used in order to interpret the way in which humans "read" technology (2006: 49). Moreover, he points out that there are certain ways in which humans can construct plots to understand technology, for example by telling about the motivations for designing a technology (2002: 4). However, taking into considerations the lessons learned from theories of technological mediation, we want to make explicit the ways humans and technologies co-shape each other by using the concept of narrative technologies. In other words, we argue that humans do not only read technologies, but technologies on the other hand "read" the human. If we then take Ricoeur's narrative theory serious, we need to see the "reading" as a reciprocal process. Therefore, the term "configuration" as it is used in mimesis 2 seems more suitable here, implying that a configuration of the technology by humans denotes a corresponding configuration of the human by technology.

Let us then briefly reflect upon the characteristics of emplotment that can be found in the design and use of technologies. In order to defend the claim that technologies configure our narrative understanding we need to show that-just as texts - they are involved in the organisation of events. Moreover, we need to defend the claim that the organisation of events includes both chronological and a-chronological dimensions of narrative time. As a starting point, we consider the way technology design is characterised in design literature to ascertain a clearly narrative structure that is used to characterise the functioning of technologies. We might consider the passage about the "confirmation principle" in technology design as captured by Lidwell et al. as an example:

Confirmation using a dialog involves establishing a verbal interaction with the person using the system. It is most commonly represented as a dialog box on a software display (e.g., "Are you sure you want to delete all files?"). In this method, dialog boxes directly ask the user if the action was intended and if they would like to proceed. (2003: 44; emphasis added)

In this passage, which serves as a guideline for design, heterogeneous factors including characters (people and, more specifically, users), events (action, verbal interaction, representation), and motives (want and intention) are brought together in a coherent whole, in a plot. However, we do not only want to show that designers use narrative approaches to understand the technologies they create; we want to go further by showing that technologies themselves configure a plot. In the use of a technology, both the technology and the user configure an organisation of events. For example, when using a car a driver enters the car, puts his seat in the right 
position, adjusts the mirrors, starts the engine, is given visual feedback about the amount of gas in the tank, drives away from the parking spot. These events are implied in the way the technology is constructed and the way the human understands it, the car configures them. However, the sequence is not strictly chronological. Some events are determined in a chronological order, like starting the engine before driving away. In contrast, adjusting the seat or the mirrors can be done in many different orders; such events are organised according to an a-chronological dimension. Moreover, applied to technology the a-chronological dimension of configuration also means that one of the events only makes sense within the larger whole. For example, adjusting the mirrors refers back to the driving plot as a whole and indeed to the practice-as-narrative: it ties in with the narrative about what good, virtuous driving is (e.g., driving includes taking into account and responding to the actions of others).

This notion that both technology and humans configure an organisation of events is important since it conceptualises, from within a narrative approach, a key insight in contemporary philosophy of technology since Heidegger: technologies are not mere instrumental means, but co-shape human meaning and human action. We claim that humans and technology configure the narrative practices in which they are involved, and do so in a way that involves public, social time. The entanglements of humans and technologies do not take place in a timeless world; there is a narrative time, there is a plot.

Thus, by using Ricoeur we can convincingly support the claim that technologies have the capacity to configure plots, understood as organisations of events. However, we need to expand the theory of narrative technologies in order to understand the different ways in which technologies are involved in the configuration of narrative time. From here, we will further theorise the relation between technology designs and the kind of narrative they instantiate.

\section{Hermeneutics of Narrative Technologies}

We employ Ricoeur's narrative theory in order to present a structured approach to understanding technologies according to their narrative capacity. With "narrative capacity," we refer to the extent to which a technology closes in on the paradigm of a text. Since we consider narrative as an ontological category (as a condition for human, socially embedded experience), we argue that narrative structures mediate all human interactions with technologies. However, we argue that the narrative capacity of technologies increases whenever technologies get more textual. For instance, although an ancient technology like fire is embedded within a cultural and symbolic, narratively prefigured time (e.g., as a symbol of progress, of war, of civilization), it is far from being itself textual; remaining close to the non-textual character of the natural world. At the other side of the hermeneutic spectrum, one finds technologies like bookkeeping systems. These technologies are highly textual: they are made up of linguistic elements and textually represent specific aspects of the human life world. 
In our theoretical framework, we refer to technologies that are far removed from the paradigm of the text as passive narrative technologies. They configure human reality, but predominantly so as elements of human prefigured time (mimesis 1 ). Conversely, we refer to technologies that are very proximate to the paradigm of the text as active narrative technologies (mimesis $\left.{ }_{2}\right)$. Those technologies actively configure prefigured human time by organising represented characters and events in a plot. Accordingly, the first hermeneutic distinction we apply to analyse narrative technologies is concerned with the extent to which technologies are capable of constituting an active process of configuration. One can think of this distinction by considering the degree of "authorship" of both humans and technologies. Although all technologies involve some degree of "co-authorship" in organising events, certain technologies are more active than others in configuring our narrative understanding. What we call passive narrative technologies in our theory refers to technologies that are part of narrative structures that are mainly created by humans, whereas what call active technologies play a larger role in co-creating the narrative structures. This first hermeneutic distinction captures the relation between language and technology that we have shown to be missing in most of the works of contemporary philosophy of technology. By analysing technologies according to the way they configure a narrative plot, or more specifically how they organise characters and events in a meaningful whole, we can understand the way they linguistically mediate human experience.

Next to the abovementioned distinction between active and passive narrative technologies, Ricoeur's theory shows us that narrative technological mediation can either stay very close to the world of human action or be abstracted from it. ${ }^{4}$ Here the question is one of distance: distance between the configured narrative structure and the technologically mediated world of human action. Similar to abstracting texts, the mediations of abstracting narrative technologies are removed from the realm of action by means of configuring quasi-characters and quasi-events in a plot. These are what Ricoeur calls second- and third-order entities: they are not actual characters or events but abstract versions of these first-order entities. The process that leads to these abstractions is typical for modern technologies, most notably for modern "time" technologies (clocks, recording devices). Ricoeur writes that modern machines that measure time enable an abstract representation of time: "Care to the world's light, saying-now retains its existential meaning, but when the machines that serve to measure time are divested of this primary reference to natural measures, that saying-now returns to the abstract representation of time" (1983: 63). Modern times are, literally, made possible by new technologies of timing, which create a distance between natural phenomena such as the sun (and shadow) and the experience of time. The technologies have changed the way we live and have altered the narratives of our lives and of our societies. Similarly to the technology of the modern clock, Fordist production technologies such as the conveyer belt abstract from the narrative of engaging labour of the artisan.

\footnotetext{
${ }^{4}$ With regards to technology, this distinction can notably be found in Heidegger's (1977) essay The Question Concerning Technology.
} 
Thus, the second hermeneutic distinction we apply in our theory to analyse narrative technologies is concerned with the extent to which technological mediation abstracts from the realm of human action. Abstracting narrative technologies create a distance between the narrative structure they configure and the world of action that revolves around a narrative of actual characters and events. Conversely, engaging narrative technologies capture the other end of the hermeneutic spectrum: they do not abstract, but configure a narrative as a direct interaction between characters in actual events; similar to the Greek tragedy Aristotle wrote about in Poetics. Although the potential for technologically mediated abstraction in the modern world is increasing, most notably in the form of ICTs, modern technologies are also capable of engaging people (as for example in the case of video games as will be discussed below). Note that this second distinction effectively captures the social dimension of narrative technologies, for these degrees of abstraction mediate intersubjective (or "being-with-others") relations. Engaging narrative technologies, ones that remain close to the configuration of a plot, organise events and characters in a public, social time. Abstracting narrative technologies construct quasi-characters and quasi-events that comprise multitudes of social relations (as is for instance the case with quasi-characters like markets, companies, and nation states). Thus, by introducing this second hermeneutic distinction we are able to explicitly incorporate the social in our account of technological mediation.

As a result of our construction of the two hermeneutic distinctions that we apply to understand the notion of narrative technologies, we present a matrix with four hermeneutic categories. These categories represent conceptual spaces that capture the intersections of the extremes of the two distinctions. While working with these categories, one needs to recall that the differences implied in the hermeneutic distinctions (between passive and active; engaging and abstracting narrative technologies) are differences in degree rather than in kind, because they depend on an interpretation of the technology. In accordance with the "empirical turn" in philosophy of technology, this ties in with the idea that inquiries into the narrative capacity of technologies need to be empirically informed. Only through empirical reflections, the degree of activity and abstraction of narrative technologies can be established. Below, we present our matrix that incorporates the hermeneutic categories, each of which is illustrated by means of a paradigmatic example of a narrative technology.

\section{Analyses of Narrative Technologies: The Hermeneutic Categories Set to Work}

Thus far, we have presented our theoretical framework of narrative technologies according to the two hermeneutic distinctions we discussed. In this last section, we will demonstrate the merits of our framework by engaging in separate discussions of the four hermeneutic categories that revolve around paradigmatic examples of narrative technologies displayed in our matrix (Table 1): the wooden bridge, the hydroelectric plant, video games, and electronic money. 
Table 1 Overview of the hermeneutic categories of narrative technologies, including paradigmatic examples narrative technologies that fit these categories

\begin{tabular}{lll}
\hline Narrative technologies & Engaging & Abstracting \\
\hline Passive & Bridge & Hydroelectric plant \\
Active & Video games & Monetary technologies \\
\hline
\end{tabular}

\section{Passive, Engaging Technologies}

The first hermeneutic category in our framework is concerned with narrative technologies that are passive elements of our narrative time and mediate organisations of first order events and characters. We discuss the paradigmatic example of the wooden bridge, as it figures in Heideggers essay The Question Concerning Technology. He argues that the bridge is "built into the Rhine River" and "joined bank with bank for hundreds or years" (1977: 16). An important element of Heideggers analysis is the notion that the bridge has been part of the human life world for multiple generations. However, at the time when it was built, it did configure human narrative time by organising characters and events (merchants, armies, trades, and wars) in a narrative whole. In other words, the bridge actively configured the narrative time of the people interacting with the bridge once it was build. However, at the point where the time of the bridge surpassed the time of the humans who build it, it gradually became a passive element of the prefigured narrative time. That is, the bridge became an element of the cultural "repertoire" of the humans interacting with it and it an element of narratives about the bridge, authored by humans (as in Hölderlin's hymn mentioned by Heidegger). That the wooden bridge is an engaging technology can be argued for by considering the characters and events it instantiates. Although those who interact with the bridge are always placed in a narrative time (they are not anonymous bridge-crossers but rather travellers, merchants, soldiers), the organisation of characters and events they engage in by means of interaction with the bridge is close to the world of action. The social relations that are configured by this interaction are relations of first order characters (for example of merchants) engaging in first order events (for example in a trade of agricultural products).

\section{Passive, Abstracting Technologies}

The second hermeneutic category in our framework is concerned with narrative technologies that are passive elements of our narrative time and instantiate a technological mediation that abstracts from the world of action. Again, consider Heidegger's The Question Concerning Technology, which provides another paradigmatic example of technology: the hydroelectric plant (1977: 16). The Rhine supplies hydraulic pressure, which sets the turbines turning and creates electric current. Now this power plant is a passive narrative technology in the sense that it predominantly has a place in prefigured narrative time. When it was 
built, it actively configured the narrative of energy production and consumption: configuring workers, consumers, working shifts, and emergency plans. But in the passing of human time it has become part of the way things are done. Things are following their normal course, literally. The plant has become part of the narrative time of hydraulic energy, of its cultural repertoire, which was written in the past by humans. However, in contrast to the bridge the power plant is not an engaging but rather an abstracting narrative technology. It has been removed from the world of action of its surroundings. It has configured a narrative structure of characters and events (mechanics, people consuming power in their houses), but is itself removed form that narrative. Whereas the wooden bridge instantiates a configuration of first-order characters and events, placed in narrative time, the hydroelectric plant configures quasi-characters and quasievents such as energy markets, energy grids, energy companies, and 'interlocking processes' - to use Heidegger's words again. The energy markets, the energy grids and so on are not first-order characters, and their configuration does not constitute first-order events. There is a 'system' (according to Heidegger: a process of 'enframing'). The narrative is abstracted by means of the configuration of higher-order entities. It is not experienced as being about actual characters and events, close to the realm of human action, but it has become abstracted from the people who work at the plant and the people who use electricity. Moreover, the hydroelectric plant configures a narrative structure that predominantly revolves around chronological time dimensions vis-à-vis a-chronological time dimensions. The "proper" functioning of the plant requires strict sequences of events, dictated by the time technologies like the clock (working shifts, regular controls of the machinery).

\section{Active, Engaging Technologies}

The third hermeneutic category in our framework is concerned with narrative technologies that actively configure human narrative time and mediate organisations of first order events and characters. We will discuss a paradigmatic type of technologies that are capable of engaging people in a narrative structure: video games. First of all, we consider the degree of active configuration. All forms of human-computer interaction involve mediation by symbolic and textual information. ICTs and humans often "co-author" and "co-act" the narratives they engage in and co-constitute. This, in turn, influences the configuration of both the human and the technology. Thus, in contrast to passive narrative technologies active narrative technologies like video games continue to configure narrative structures whenever people interact with them. In a video game, a narrative plot is configured in which a character (more commonly referred to as an avatar) interacts with a virtual world that includes other characters and virtual events. Events in a game are organised in a narrative whole, in the plot of the game. ${ }^{5}$ In this process of emplotment, the character's actions influence the unfolding of the narrative. At the same time, the

\footnotetext{
5 Notably, the notion of narrative plays an important role in the design of virtual environments (Aylett 1999).
} 
specific organisations of events and characters of the game configure the actions of the avatar. The plot and narrative are thus continuously co-authored by the technology and the humans. Secondly, we can consider the degree of abstraction in technological mediation by video games. This differs according to the type of game that is played, but in general the configuration of the plot remains close to the world of human action. The characters interact as in a theatre play: directly with other characters through actual events (for instance through combat, barter, and discourse). Moreover, the organisation of events is not strictly chronological, but includes a-chronological dimensions. A video game can include oscillations between separate events and the plot as a whole (for example by relating "missions" to "campaigns"), it can include a sense of ending and players might have the opportunity to "read" time backwards (by means of flashbacks or flash-forwards). This brings technological mediation through computer games close to the experience of human time, close to the engaging world of action.

\section{Active, Abstracting Technologies}

The fourth hermeneutic category in our framework is concerned with narrative technologies that actively configure our narrative time and instantiate a technological mediation that abstracts from the world of action. Here we discuss electronic monetary technology as a paradigmatic example. Consider the practice of electronic trading. On global financial exchanges, algorithmic trading systems mediate trades by representing transactions on the trading screen and by mediating trade executions: trade is effectively delegated to algorithms that conduct trades much faster than humans and can therefore take advantage of very small price differences. Such algorithmic trading technologies actively configure narrative time because they "co-author" the trade narrative. The trade is done by humans and by algorithms; together they configure the narrative structure. However, unlike engaging narrative technologies like video games, they do this in a way that abstracts from the narrative they instantiate. Although they mediate actual events (trades) and actual characters (traders), the narrative time they configure is remote from the level of human action and instead operates on a calculative, mathematical level. Phenomenologically and hermeneutically speaking, the trade is about numbers that represent quasi-characters (hedge funds, options, securities) and quasi-events (derivative trades, currency swaps) configured in a quasi-plot (e.g., "the flash crash" ${ }^{\text {) }}$ ) and no longer about first-order characters (traders, producers) and events (a person can no longer sell a good because the price-a higher-order entity-has gone up). Moreover, the narrative time of electronic monetary technologies is rigorously subjected to chronological time-dimensions. Chronological timing of trades is the essence of modern trading machines and the sequence of the operations for the execution of transactions is critical to the functioning of the

\footnotetext{
6 The flash crash was "a brief period of extreme market volatility on May 6, 2010," that was influenced by the practice of algorithmic high frequency trading (Kirilenko et al. 2011: 1).
} 
system. Modern finance, in other words, nearly obliterates the a-chronological aspects of the trading narrative. ${ }^{7}$

\section{Conclusion and Discussion}

In this paper we have shown how Ricoeur's narrative theory can be used to construct a theoretical framework for understanding technological mediation. By doing so, we respond to the current neglect of language and the social in theories of technological mediation in philosophy of technology. The concept of narrative technologies helps us to analyse the temporal dimensions of technologies, highlight their social and linguistic aspects, and re-theorise their mediating role in terms of their narrative capacities. The framework we constructed is based on two hermeneutic distinctions: between active, passive and between engaging, abstracting narrative technologies. We considered the extent to which technologies are similar to the paradigm of the written text by examining how they actively configure characters and events in a meaningful whole (instantiating a process of emplotment). By doing so, we were able to analyse how the linguistic and material aspects of technologies interrelate. Moreover, we considered the extent to which technologies configure narrative structures that are abstracted from the world of action. We did so by examining the configuration of second- and third order entities and the inclusion of chronological visà-vis a-chronological time dimensions. The value of our narrative approach lies explicitly and mainly in gaining novel insights about the active configuration of technologies such as ICTs and perhaps less so in the understanding of passive narrative technologies since these can already be analysed by means of existing approaches in philosophy of technology focusing on mediation.

By means of our theory of narrative technologies, we have constructed a hermeneutic framework that helps us to understand how technologies configure intersubjective relations and how these relations can be traced back to the subjective realm of human action. By doing so, we can capture the difference between what in mediation theory is referred to as the difference between macroperception (cultural, hermeneutic perception) and microperception (sensory perception) (Verbeek 2005: 123). In contrast to mediation theory, however, we can relate the sometimesabstracted mediations of intersubjective relations with the subjective experiences of these mediations by means of retrodiction. In a similar vein, we can confront theories in the analytic philosophical tradition that base the construction of the world of technology on the workings of language. For instance, our theory can be employed to critically assess and enrich John Searle's Construction of Social Reality (1995) by showing how intentionality at the individual level relates to collective intentionality. Instead of stating, as Searle does, that these levels relate to different primitive biological processes, we can show how narrative structures and narrative technologies enable people to engage with one-another in a social, technologically mediated world. In further work, we intend to elaborate on the ways in which our

\footnotetext{
7 Narrative capacities of electronic monetary technologies are discussed more in-depth in a paper on crypto currencies as narrative technologies (Coeckelbergh and Reijers 2015).
} 
theory of narrative technologies relates to other theories of technology and how we can expand the method of retrodiction in our analysis of specific technologies.

As an avenue for future research, we might explore ways in which technologies explicitly mediate the public experience of time and analyse the political aspects of such mediation. In light of one of Ricoeur's latest works, Memory, History, Forgetting, we can inquire how technologies shape those things that we remember, those things that we forget and thereby also the ways we relate to our personal and collective histories. One of the aims of Ricoeur's book is to construct ideas about policies for "just allotment of memory" (2004: xv). As much as political authorities and historical representations as elements of the "human historical condition" can "stand in" for our collective past (Kelly 2006: 677), so-we would argue-can technologies. Such a view suggests that, just as a historical narrative can "stand in" or "re-present" a collective memory of a past event, so can technologies "stand in" for a past event; or at least configure it in a specific way. This observation ties in with debates on for instance the so-called "right to be forgotten" (Rosen 2012) about personal rights to control the presence or absence of digital memories, which arguably for the first time explicitly puts the technological mediation of human memory on political agendas. Such a focus on the technological mediation of public time as a social and political issue might add to current phenomenological approaches in sociology, such as Shutz's Phenomenology of the Social World, by analysing how technologies can influence the "worlds of direct experience, of contemporaries, of predecessors and of successors" (2012: 45).

Moreover, we might consider the prospects for deploying the theory of narrative technologies as an ethical theory of technology. In Time and Narrative, Ricoeur asserts that a narrative structure "presupposes not just 'doers' but characters endowed with ethical qualities that make them noble or vile" (1983: 59). This suggests a link between Ricoeur's theory and virtue ethics, which could be applied to evaluating new technologies. More generally, by incorporating Ricoeur's theory, our framework can be considered not merely hermeneutic but also normative: the extent to which technologies actively configure narrative structures, and the extent to which they abstract from the world of action, has implications for evaluating technologies, and in particular specific human-technology relations. For instance, distances between first order and higher order entities can be normatively significant. As an illustration, we can observe that the world of finance and economics is characterised by such distances. For example, a character such as 'the market' is a third order, abstract entity. Through the mediation of technologies that represent the market in terms of abstract numbers, the human narrative time of first order characters and events behind it remain invisible (Coeckelbergh and Reijers 2015). The transactions become a matter of calculations, removed from real people, real events, and related material realities, thereby creating moral and social distance (Coeckelbergh 2015b). It is the task of an ethics of narrative technologies to make such problematic narrative structures visible, and to make recommendations for dealing with these problems.

Acknowledgments The ADAPT Centre for Digital Content Technology is funded under the SFI Research Centres Programme (Grant 13/RC/2106) and is co-funded under the European Regional Development Fund. Open access funding provided by University of Vienna. 
Open Access This article is distributed under the terms of the Creative Commons Attribution 4.0 International License (http://creativecommons.org/licenses/by/4.0/), which permits unrestricted use, distribution, and reproduction in any medium, provided you give appropriate credit to the original author(s) and the source, provide a link to the Creative Commons license, and indicate if changes were made.

\section{References}

Achterhuis, H. (Ed.). 2001. American philosophy of technology: The empirical turn. Bloomington and Indianapolis: Indiana University Press.

Aristotle. (1902). Poetics. In S. H. Butcher (Ed.), The Poetic. London: Macmillan and Co.

Aylett, R. (1999). Narrative in virtual environments-towards emergent narrative. In Working notes of the narrative intelligence symposium. 83-86.

Bergstra, J. A., \& Leeuw, K. De. (2013). Bitcoin and beyond: exclusively informational money. Informatics Institute, University of Amsterdam, 1-82.

Bilimoria, P. (1998). Towards a creative hermeneutic of suspicion: Recovering Ricoeur's intervention in the Gadamer-Habermas debate. Paideia, Twentieth World Congress of Philosophy.

Coeckelbergh, M. (2015a). Language and technology: Maps, bridges and pathways. AI and Society. doi:10.1007/s00146-015-0604-9.

Coeckelbergh, M. (2015b). Money Machines. Farnham: Ashgate.

Coeckelbergh, M., \& Reijers, W. (2015). Cryptocurrencies as narrative technologies. In SIGCAS Computers and Society. 45, 172-178.

Dowling, W. C. (2011). Ricoeur on time and narrative-an introduction to Temps et Recit. Notre Dame: University of Notre Dame Press, xi.

Duncan, J. (2005). Sartre and realism-all-the-way-down. Sartre Studies International, 11(1-2), 91-113.

Feenberg, A. (1999). Questioning technology. New York: Routledge.

Goodfellow, R., \& Hewling, A. (2005). Re-conceptualising culture in Virtual Learning Environments: from an "essentialist" to a "negotiated" perspective. E-Learning and Digital Media, 2(4), 355-367.

Hassam, A. (1990). "As I Write": Narrative occasions and the quest for self-presence in the travel diary. ARIEL: A Review of International English Literature, 21(4), 33-47.

Heidegger, M. (1977). The question concerning technology. New York: Garland Publishing.

Hess, C., \& Ostrom, E. (2003). Ideas, artifacts, and facilities: information as a common-pool resource. Law and Contemporary Problems, 66(1), 111-145.

Ihde, D. (2009). Postphenomenology and technoscience. New York: Sunny Press.

Jenkins, H. (2003). Game design as narrative architecture. Response, 44(3), 1-15.

Jones, C. F., Loh, S.-L., \& Sato, K. (2013). Narrating Fukushima: Scales of a nuclear meltdown. East Asian Science Technology and Society, 7(4), 601-623.

Kaplan, D. M. (2002). The story of technology. Drexel University. Retrieved February 18, 2016, http:// www.pages.drexel.edu/ pa34/The\%20Story\%20of\%20Technology.pdf.

Kaplan, D. M. (2006). Paul Ricoeur and the philosophy of technology. Journal of French and Francophone Philosophy, 16(1-2), 42-56.

Kaplan, D. M. (2009). What things still don't do. Human Studies, 32(2), 229-240.

Kelly, M. R. (2006). Review of memory, history, forgetting. The Review of Metaphysics, 59(3), 675-677.

Kirilenko, A. a., Kyle, A. S., Samadi, M., \& Tuzun, T. (2011). The flash crash: The impact of high frequency trading on an electronic market. SSRN Electronic Journal.

Lessig, L. (2006). CODE version 2.0. CODE version 2.0. New York: Basic Books.

Lidwell, W., Holden, K., \& Butler, J. (2003). Universal principles of design. Beverly: Rockport Publishers.

Macintyre, A. (2007). After virtue: A study in moral theory (Third Edit). Notre Dame, Indiana: University of Notre Dame Press.

Mateas, M., \& Sengers, P. (1999). Narrative intelligence. In Proceedings AAAI Fall Symposium on Narrative Intelligence, 1-10.

Meretoja, H. (2014). Narrative and human existence: Ontology, epistemology, and ethics. New Literary History, 45(1), 89-109. 
Mink, L. O. (1970). History and fiction as modes of comprehension. New Literary History, 1(3), 541-558.

Patterson, D. M. (1990). Law's pragmatism: Law as practice and narrative. Virginia Law Review, 76(5), 937-996.

Ricoeur, P. (1971). The model of the text: Meaningful action considered as a text. Hermeneutics and Critical Theory, 38(1), 316-333.

Ricoeur, P. (1980). Narrative time. Critical Inquiry, 7(1. On Narrative), 169-190.

Ricoeur, P. (1983). Time and narrative-Volume 1. In K. McLaughlin \& D. Pellauer (Eds.), Chicago: The University of Chicago.

Ricoeur, P. (1985). Time and narrative-Volume 2. In K. McLaughlin \& D. Pellauer (Eds.), Chicago: The University of Chicago.

Ricoeur, P. (2004). Memory, history, fogetting. In K. Blamey \& D. Pellauer (Eds.), Chicago: The University of Chicago Press.

Ricoeur, P. (2014). The later Wittgenstein and the later Husserl on language. Études Ricoeuriennes/ Ricoeur Studies, 5(1), 28-48.

Rosen, J. (2012). The right to be forgotten. Stanford Law Review, 64(88), 88-92.

Schutz, A. (2012). The phenomenology of the social world. In C. Calhoun, J. Gerteis, J. Moody, \& S. Pfaff (Eds.), Contemporary sociological theory. New York: John Wiley \& Sons Ltd.

Searle, J. R. (1995). The construction of social reality. London: Penguin Group.

Strawson, G. (2004). Against narrativity. Ratio, XVII 4.

Taylor, C. (1971). Interpretation and the sciences of man. The Review of Metaphysics, 25(1), 3-51.

Van Den Eede, Y. (2010). In between us: On the transparency and opacity of technological mediation. Foundations of Science, 16(2-3), 139-159.

Van Dijk, T. (1974). Philosophy of action and theory of narrative. Poetics, 5(4), 287-338.

Verbeek, P.-P. (2005). What things do; philosophical reflections on technology, agency, and design. Pennsylvania: Pennsylvania University Press.

White, H. (1980). The value of narrativity in the representation of reality. Critical Inquiry, 7(1), 5. 